\title{
Determining the Appropriate Values of Compactor Paramaters of the Enhanced Harrow Leveller
}

\author{
Tukhtakuziev Abdusalim, Abdulkhaev Khurshed Gafurovich*, Barlibaev Sherzod Nakibbekovich
}

Scientific-Research Institute for Agricultural Mechanization, Republic of Uzbekistan

Received March 10, 2020; Revised April 20, 2020; Accepted May 3, 2020

Copyright $\bigcirc 2020$ by authors, all rights reserved. Authors agree that this article remains permanently open access under the terms of the Creative Commons Attribution License 4.0 International License

\begin{abstract}
The following items are specified in the article: installation angle with regard of horizon of the enhanced compactor of harrow leveller for the purpose of increasing the work quality and efficiency in land areas harrowing and decreasing the energy-material consumption; length of the working surface and comparison to be forwarded to it, i.e., the results of multi-factor experiments to determine the optimal values of its vertical load corresponding to a coverage width of one meter, which provides the required level of work quality with low energy consumption. Multifactorial trials were implemented based on Hartley-4 plan. In this case the following items are obtained: mean square deviation of unevenness heights of processed land surface as evaluation criteria; degree of soil crumbling, i.e. amount of soil fractions having dimensions less than $25 \mathrm{~mm}$; density of soil at $0-10 \mathrm{~cm}$ layer and comparative resistance of traction of the harrow leveller. The information and data obtained in the course of trials was developed based on the "Planexp" programme at the Experiments and Testing Department of the Institute. In this case the following criteria were used: Cochran's test criteria for evaluating the uniformity of dispersion; Student's criteria for evaluation the value of regression coefficients; Fisher criteria for evaluation the adequateness of regression models. The results of trial were developed based on the above specified programme, thus regression equations adequately formulating the evaluation criteria were obtained. They are the average square deviation of the height of the unevenness of the field surface treated for the unit operating speeds of 6.0-8.0 $\mathrm{km} / \mathrm{h}$ which is less than $2.0 \mathrm{~cm}$, the degree of soil compaction is greater than $80 \%$, the density of the soil in the $0-10 \mathrm{~cm}$ layer is $1.1-$ In the range of $1.2 \mathrm{~g} / \mathrm{cm}^{3}$ and the conditions under which the specific resistance of the harrow leveller has a minimum value, the following optimal values of the improved harrow-leveller compactor parameters were determined: installation angle of the compactor relative to the horizon $29-32^{\circ}$, working surface length $31-32 \mathrm{~cm}$ and the vertical load applied to it is 2.4-2.6
\end{abstract}

$\mathrm{kN} / \mathrm{m}$.

Keywords Enhanced Harrow Leveller, Leveller, Compactor, Installation Angle of the Compactor with Regard to Horizon, Length of the Working Surface, Comparative Straight Tension, Multifactorial (Trials) Experiments, Regression Equations

\section{Introduction}

Transfer to intensive methods of agricultural production by introducing the up-to-date agricultural technologies and the provision of farms with high-yield agricultural machinery is the most important direction in the sustainable and efficient development of this sector.

Before sowing the cultures in producing the plenty of yield the agricultural crops it is important to process the lands qualitatively. In the event if the lands are not processed qualitatively, the agricultural crops seeds cannot be sown under the appropriate manner of agrotechnical requirements; the sown seeds will not grow (develop) with plenty and enough seedlings per a hectare which will not be obtained. Thus it outcomes in reducing the crops yield.

It is known that major tasks and assignments in lands presowing tillage are the following: leveling the lands surface; compacting in the appropriate manner and crushing large lumps in it to form fine soil layer [1]. At present, MV-6.0, MV-6.5 and other harrow levellers available on farms are widely used for this purpose in our country $[2,3]$.

But when these harrow levellers are applied in order to till the lands on appropriate level they should pass by the same place for 2-3 times. And it will lead in: increase in labor consumption and other expenditures, including the fuel consumption during lands preparation activities necessary for sowing; excessively soil compacting and losing its moisture; reducing of work effectiveness as well 
as extension the period the agricultural crops sowing out of date. Besides that, existing harrow levellers are morally very outdated. They do not correspond the up-to-date demands in lands tillage by minimum and under savings, considering above mentioned, the enhanced harrow leveller is developed at the Scientific-Research Institute of Agricultural Mechanization, researches on substantiation of its parameters are being carried out.

Enhanced harrow leveller is manufactured in suspension type and consists of the following items: frame equipped with suspension unit (not shown in the figure); levelling and compacting operation elements (further more accordingly leveller and compactor) mounted to it. In the course working process leveller will align the unevenness on the land surfaceand compactor will seal (compact) the land surface aligned by leveller (figure 1).

\section{Materials and Research Methods}

The results of multifactorial trials are in accordance with the Hartly-4 plan, in effort to determine the appropriate values under the terms and conditions with the necessary work quality (fig.1) by less energy consumption of the installation angle of compactor of the enhanced harrow-leveller with regard to horizon - $\beta$; length of working surface - $L$ and comparative straight tension forwarded to it $-Q$ are specified in the article. The factors, their designation, variation intervals and levels are given in the table 1 .

In the course of implementation, the multifactorial trials (experiments) the mean square deviation of unevenness height of the tilled field surface; degree of soil crumbling, i.e. amount, density of soil and soil fractions have dimensions less than $25 \mathrm{~mm}$, as well as comparative tension resistance of the harrow levellers were obtained as evaluation criteria; in this case they were determined by applying existing normative documents $[4,5]$.

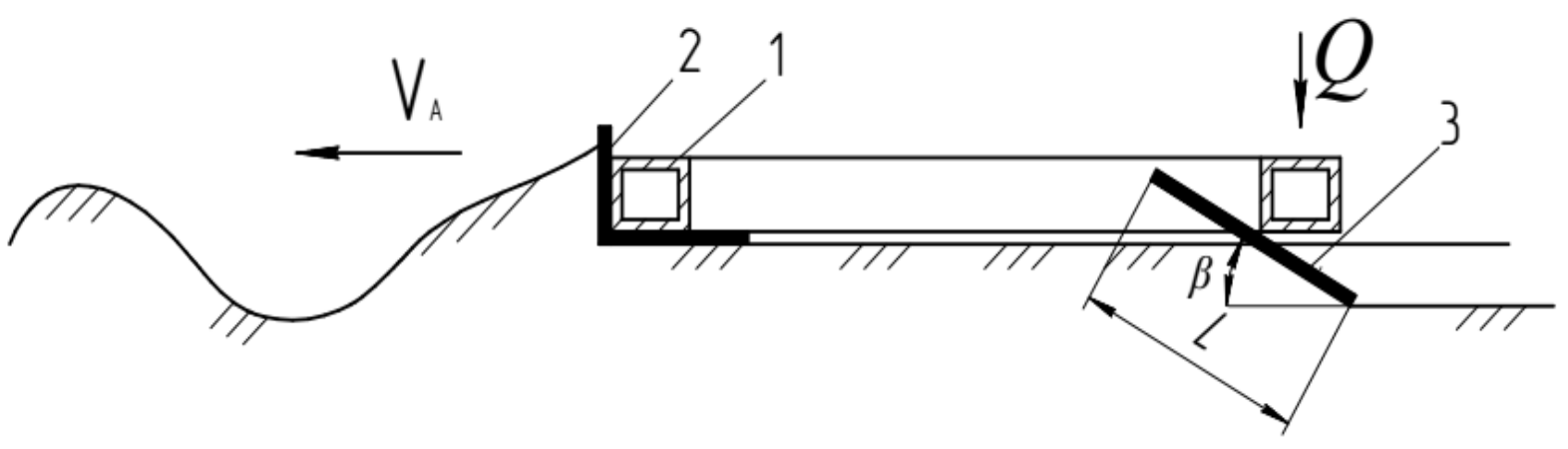

1-chassis; 2-leveller; 3-compactor

Figure 1. Technological working process and parameters of the enhanced harrow leveller

Table 1. Intervals and levels of the factors variations

\begin{tabular}{|c|c|c|c|c|c|c|c|}
\hline \multirow{3}{*}{ № } & \multirow{3}{*}{ Factors and their natural designation } & \multirow{3}{*}{$\begin{array}{l}\text { Measureme } \\
\text { nt unit }\end{array}$} & \multicolumn{5}{|c|}{ Factors } \\
\hline & & & \multirow{2}{*}{$\begin{array}{c}\text { Coding } \\
\text { designation }\end{array}$} & \multirow{2}{*}{$\begin{array}{l}\text { Variation } \\
\text { interval }\end{array}$} & \multicolumn{3}{|c|}{ levels } \\
\hline & & & & & $\begin{array}{c}\text { lower } \\
(-1)\end{array}$ & Main $(0)$ & $\begin{array}{c}\text { upper } \\
(+1)\end{array}$ \\
\hline 1. & $\begin{array}{l}\text { Installation angle of the compactor with regards } \\
\text { to horizon, } \beta\end{array}$ & degree & $\mathrm{X}_{1}$ & 10 & 20 & 30 & 40 \\
\hline 2. & Length of working surface of the compactor, $L$ & $\mathrm{~cm}$ & $\mathrm{X}_{2}$ & 5 & 25 & 30 & 35 \\
\hline 3. & $\begin{array}{l}\text { Comparative straight tension power to be } \\
\text { forwarded with regard to harrow leveller, } Q\end{array}$ & $\mathrm{kN} / \mathrm{m}$ & $\mathrm{X}_{3}$ & 0.4 & 2.0 & 2.4 & 2.8 \\
\hline 4. & Movement velocity, $V$ & $\mathrm{~km} / \mathrm{h}$ & $\mathrm{X}_{4}$ & 1.5 & 6.0 & 7.5 & 9.0 \\
\hline
\end{tabular}


In effort to determine mean square deviation of unevenness height of the tilled field surface after the harrow leveller passes by means of coordinating lath having $5 \mathrm{~m}$ length, installed on two poles horizontally, the distances from the field surfaces until upper part of lath with $5 \mathrm{~cm}$ interval were measured. According to the measurements data by methods of the mathematic statistics an average arithmetic value from the field surfaces until upper part of lath and its mean square deviation, but then the mean square deviation of unevenness heights of the surface of tilled field area by the harrow leveller.

In the event when we determine the degree of soil crumbling after the harrow levellers passing by means of bottomless box from the $0,25 \mathrm{~m}^{2}$ area at the $10 \mathrm{~cm}$ depth the samples were taken and by using sieve that has openings of $25 \mathrm{~mm}$ diameter, they were divided into fractions having dimensions of more and less than $25 \mathrm{~mm}$. After the degree of soil crumbling was determined as ratio of fractions mass of $25 \mathrm{~mm}$ with respect to total mass of sample in percent.

Soil density was determined at the layer of $0-10 \mathrm{~cm}$ by using cylinder of $10 \mathrm{~cm}$ height and volume of $500 \mathrm{~cm}^{3}$.

Specific traction resistance of small harrow leveller was determined by means of dividing its total traction resistance to the width seizure; and total traction resistance of harrow leveller was determined by means of strain gauging and here tenzofingers (fig.2) installed onto its hinged device were applied. Before and after implementing the trials the tenzofingers were calibrated.

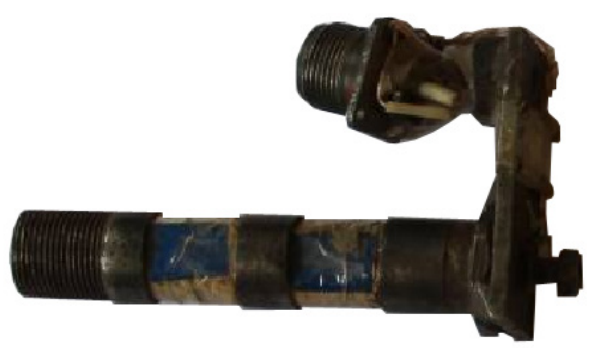

a) tenzofinger, to be installed on the upper point of hinged device of the harrow leveller;
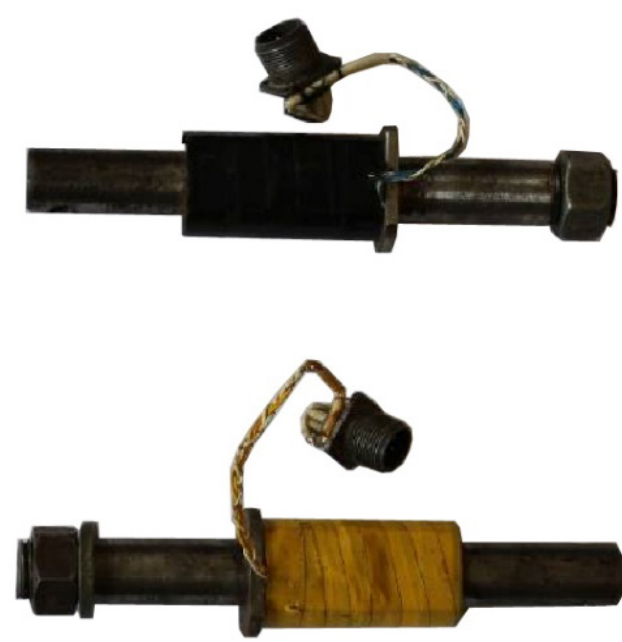

b) tenzofingers, to be installed on the lower points of hinged device of the harrow leveller

Figure 2. Tenzofingers

(1)-(4) When we analyze the regression equations and graphical relations formulated based on them, it can be found out that all the factors have influenced the evaluation criteria significantly (figures 3-5).

For the purpose of reducing the influence of physical and mechanical properties of soil and unevenness height of the tilled field surface as well as the evaluation criteria, the sequence of trials (experiments) implementation is drawn up by using the table of random numbers [6].

Results of multifactorial trials (experiment) are shown at table 2 .

The information and data obtained in the course of trials was developed based on the "Planexp" programme at the Experiments and Testing Department of the Institute. In this case the following criteria were used:

- Cochran's test criteria for evaluating the uniformity of dispersion;

- Student's criteria for evaluation the value of regression coefficients;

- Fisher criteria for evaluation the adequateness of regression models. 
Table 2. Results of multifactor trial (experiment)

\begin{tabular}{|c|c|c|c|c|c|c|c|c|c|c|c|}
\hline \multicolumn{3}{|c|}{$\begin{array}{l}\text { Mean square deviation of } \\
\text { unevenness height of the tilled } \\
\text { field }( \pm \mathrm{cm}) \text { by recurrencies }\end{array}$} & \multicolumn{3}{|c|}{$\begin{array}{c}\text { Degree of soil crumbling (\%) } \\
\text { by recurrencies }\end{array}$} & \multicolumn{3}{|c|}{$\begin{array}{c}\text { Soil density }\left(\mathrm{g} / \mathrm{cm}^{3}\right) \text { by } \\
\text { recurrencies }\end{array}$} & \multicolumn{3}{|c|}{$\begin{array}{l}\text { Specific traction resistance } \\
(\mathrm{kN} / \mathrm{m}) \text { by recurrencies }\end{array}$} \\
\hline 1 & 2 & 3 & 1 & 2 & 3 & 1 & 2 & 3 & 1 & 2 & 3 \\
\hline 1.906 & 1.917 & 1.874 & 74.36 & 74.71 & 73.27 & 0.971 & 0.976 & 0.965 & 2.408 & 2.412 & 2.395 \\
\hline 2.052 & 2.063 & 2.020 & 75.20 & 75.58 & 74.07 & 1.063 & 1.067 & 1.057 & 2.760 & 2.765 & 2.746 \\
\hline 1.067 & 1.977 & 1.934 & 73.82 & 74.20 & 72.71 & 1.09 & 1.095 & 1.084 & 2.512 & 2.513 & 2.499 \\
\hline 2.113 & 2.122 & 2.083 & 76.26 & 76.69 & 75.10 & 1.099 & 1.104 & 1.092 & 2.972 & 2.974 & 2.958 \\
\hline 1.036 & 1.942 & 1.913 & 75.30 & 75.76 & 74.06 & 1.090 & 1.094 & 1.084 & 3.392 & 3.397 & 3.376 \\
\hline 2.082 & 2.090 & 2.055 & 76.49 & 76.94 & 75.26 & 1.118 & 1.122 & 1.112 & 3.00 & 3.004 & 2.984 \\
\hline 1.405 & 1.915 & 1.87 & 77.71 & 78.13 & 76.57 & 1.093 & 1.097 & 1.087 & 3.572 & 3.576 & 3.555 \\
\hline 1.635 & 1.644 & 1.607 & 84.51 & 84.94 & 83.29 & 1.037 & 1.097 & 1.087 & 3.072 & 3.075 & 3.056 \\
\hline 1.871 & 1.881 & 1.843 & 76.04 & 76.44 & 74.90 & 1.094 & 1.098 & 1.087 & 3.073 & 3.077 & 3.058 \\
\hline 1.913 & 1.923 & 1.884 & 78.86 & 79.27 & 77.68 & 1.112 & 1.116 & 1.105 & 3.053 & 3.057 & 3.038 \\
\hline 1.754 & 1.762 & 1.729 & 81.76 & 82.21 & 80.49 & 1.133 & 1.137 & 1.127 & 2.691 & 2.696 & 2.677 \\
\hline 1.563 & 1.572 & 1.537 & 86.45 & 86.87 & 85.20 & 1.159 & 1.163 & 1.153 & 2.885 & 2.888 & 2.870 \\
\hline 1.788 & 1.797 & 1.762 & 81.34 & 81.78 & 80.11 & 1.114 & 1.119 & 1.108 & 2.420 & 2.423 & 2.407 \\
\hline 1.566 & 1.574 & 1.543 & 86.65 & 87.11 & 85.33 & 1.156 & 1.160 & 1.150 & 2.956 & 2.960 & 2.940 \\
\hline 1.764 & 1.772 & 1.740 & 83.46 & 83.91 & 82.17 & 1.158 & 1.162 & 1.152 & 2.699 & 2.702 & 2.684 \\
\hline 1.514 & 1.523 & 1.489 & 87.49 & 87.93 & 86.22 & 1.133 & 1.137 & 1.127 & 3.119 & 3.122 & 3.105 \\
\hline 1.639 & 1.648 & 1.614 & 84.77 & 85.21 & 83.50 & 1.153 & 1.137 & 1.147 & 2.829 & 2.832 & 2.814 \\
\hline
\end{tabular}

\section{The Results of Research and Discussing Them}

The following regression equations were obtained that adequately specify the evaluation criteria after developing onto the results according to the set programme:

- by mean square deviations of unevenness height of the tilled field surface, $( \pm \mathrm{cm})$

$Y_{1}=1.634+0.021 \mathrm{X}_{1}-0.096 \mathrm{X}_{2}-0.111 \mathrm{X}_{3}-0.125 \mathrm{X}_{4}+0.252 \mathrm{X}_{1}^{2}$ $-0.052 \mathrm{X}_{1} \mathrm{X}_{2}-0.052 \mathrm{X}_{1} \mathrm{X}_{3}-0.052 \mathrm{X}_{1} \mathrm{X}_{4}+0.019 \mathrm{X}_{2}^{2}+0.05 \mathrm{X}_{2} \mathrm{X}_{3}+$ $+0.051 \mathrm{X}_{2} \mathrm{X}_{4}+0.038 \mathrm{X}_{3}^{2}+0.051 \mathrm{X}_{3} \mathrm{X}_{4}$;

- $\quad$ by degree of soil crumbling, (\%)

$Y_{2}=84.496+1.405 \mathrm{X}_{1}+2.343 \mathrm{X}_{2}+2.643 \mathrm{X}_{3}+1.395 \mathrm{X}_{4}$ $-7.298 \mathrm{X}_{1}^{2}+0.899 \mathrm{X}_{1} \mathrm{X}_{2}+0.586 \mathrm{X}_{1} \mathrm{X}_{3}+0.498 \mathrm{X}_{1} \mathrm{X}_{4}-$ $-0.666 \mathrm{X}_{2}^{2}-0.852 \mathrm{X}_{2} \mathrm{X}_{4}-0.776 \mathrm{X}_{3}^{2}-0.3971 \mathrm{X}_{3} \mathrm{X}_{4}+0.7 \mathrm{X}_{4}^{2} ;(2)$

- by soil density, $\left(\mathrm{g} / \mathrm{cm}^{3}\right)$

$$
\begin{aligned}
Y_{3}= & 1.140+0.009 \mathrm{X}_{1}+0.01 \mathrm{X}_{2}+0.021 \mathrm{X}_{3}-0.012 \mathrm{X}_{4^{-}} \\
& -0.05 \mathrm{X}_{1}^{2}-0.021 \mathrm{X}_{1} \mathrm{X}_{2}-0.016 \mathrm{X}_{1} \mathrm{X}_{3}+0 \mathrm{X}_{1} \mathrm{X}_{4^{-}} \\
& -0.007 \mathrm{X}_{2}^{2}-0.017 \mathrm{X}_{2} \mathrm{X}_{3}-0.011 \mathrm{X}_{3}^{2}
\end{aligned}
$$

- by the traction comparative resistance of harrow leveller, $(\mathrm{kN} / \mathrm{m})$

$$
\begin{aligned}
& Y_{4}= 2.825-0.010 \mathrm{X}_{1}+0.097 \mathrm{X}_{2}+0.268 \mathrm{X}_{3}+0.210 \mathrm{X}_{4}+ \\
&+0.234 \mathrm{X}_{1}^{2}-0.213 \mathrm{X}_{1} \mathrm{X}_{3}-0.027 \mathrm{X}_{1} \mathrm{X}_{4}-0.041 \mathrm{X}_{2}^{2}-0.218 \mathrm{X}_{2} \mathrm{X}_{3}+ \\
&+ \\
&+0.03 \mathrm{X}_{2} \mathrm{X}_{4}-0.07141 \mathrm{X}_{3}^{2}-0.026 \mathrm{X}_{3} \mathrm{X}_{4}+0.08 \mathrm{X}_{4}^{2} .(4)
\end{aligned}
$$

Equations (1)-(4) are applicable in the event if $20^{\circ} \leq \beta \geq 40^{\circ} 25 \mathrm{~cm} \leq L \geq 35 \mathrm{~cm}, 2.0 \mathrm{kN} / \mathrm{m} \leq Q \geq 2.8 \mathrm{kN} / \mathrm{m}$, $6.0 \mathrm{~km} / \mathrm{h} \leq V \geq 9.0 \mathrm{~km} / \mathrm{h}$.

(1)-(4) When we analyse the regression equations and graphical relations formulated based on them, it can be found out that all the factors have influenced the evaluation criteria significantly (figures 3-5).

Installation angle of the compactor with regard to horizon, i.e.as the $X_{1}$ factor increases $Y_{1}$ and $Y_{4}$ criteria, that is deviation of height of the mean square unevenness on the field surface and before comparative resistance to the traction decreased, after it has enlarged; $Y_{2}$ and $Y_{3}$ criteria, i.e. before degree of the soil crumbling and density has reduced, after it increased. 

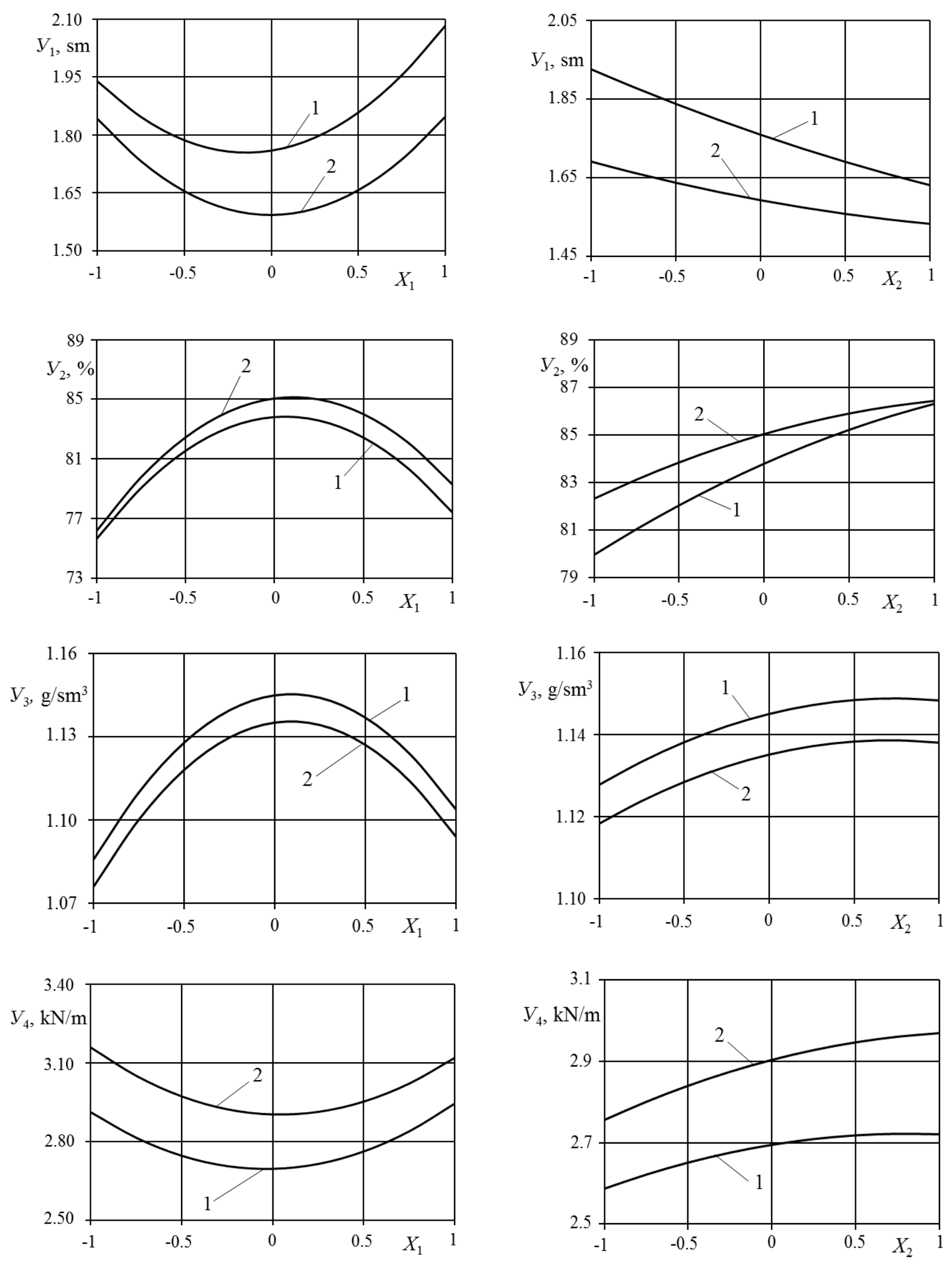

In case when 1 and 2 - accordingly velocity of movement were 6.0 and $8.0 \mathrm{~km} /$ hour

In case when 1 and 2 - accordingly velocity of movement were 6.0 and $8.0 \mathrm{~km} /$ hour

Figure 3. Variation curves of $Y_{1}, Y_{2}, Y_{3}$ and $Y_{4}$ criterias in relation with $X_{1}$ factor

Figure 4. Variation curves of $Y_{1}, Y_{2}, Y_{3}$ and $Y_{4}$ criterias in relation with $X_{2}$ factor 

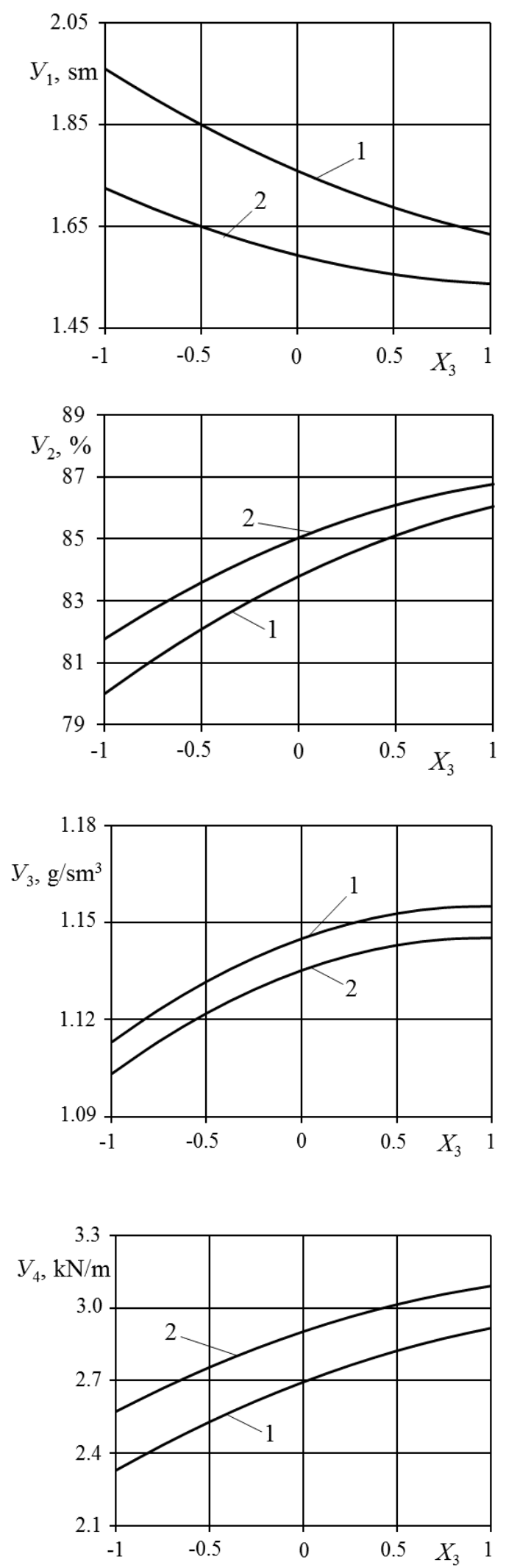

In case when 1 and 2 - accordingly velocity of movement were 6.0 and 8.0 $\mathrm{km} /$ hour

Figure 5. Variation curves of $Y_{1}, Y_{2}, Y_{3}$ and $Y_{4}$ criterias in relation with $X_{3}$ factor
$X_{2}$ factor, i.e. as the length of working surface of compactor increases $Y_{1}$ criteria almost decreased based on the straight line laws; and $Y_{2}, Y_{3}$ and $Y_{4}$ criteria enlarged, but as $X_{2}$ enlarges their increase, intensity has decreased.

Influence forwarded onto the straight comparative tension was as in $X_{2}$ criteria to critearia of $X_{3}$ factor. And whenever such criteria increases $Y_{1}$ criteria has decreased. $Y_{2}, Y_{3}, Y_{4}$ criteria has enlarged.

(1)-(4) regression equations are less than $Y_{1}$ criteria 2,0 $\mathrm{cm}, Y_{2}$ criteria is more than $80 \% ; Y_{3}$ criteria bet ween $1,1-1,2 \mathrm{~g} / \mathrm{cm}^{3}$ and $Y_{4}$ criteria may be together solved due to that they have minimum values; the following appropriate values for the working velocities - 6.0-8.0 km/h of compactor parameters of the enhanced harrow leveller were found: installation angle of compactor with regard to horizon is $29-32^{\circ}$; length of working surface is $31-32 \mathrm{~cm}$ and straight load forwarded to it is $2.4-2.6 \mathrm{kN} / \mathrm{m}$.

$Y_{1}, Y_{2}, Y_{3}$ and $Y_{4}$ criteria accordingly will be $1.53-1.71 \mathrm{~cm}$, $84.49-86.75 \%, 1.14-1.15 \mathrm{~g} / \mathrm{cm}^{3}$ and $2.67-3.24 \mathrm{kN} / \mathrm{m}$ in the determined above values of the factors.

\section{Conclusions}

According to the results of implemented multifactorial experiments $6.0-8.0 \mathrm{~km} / \mathrm{h}$ the following items were pointed out: in effort to ensure performing the necessary tillage on the field surface when the movement velocity of the enhanced harrow leveller compactor by consuming the less energy, in this case the installation angle of compactor with regard to horizon should be between 29-32 ; length of the working surface - between $31-32 \mathrm{~cm}$ and straight tension forwarded to it should be $2.4-2.6 \mathrm{kN} / \mathrm{m}$.

\section{REFERENCES}

[1] Sample technologic maps of cultivating the agricultural crops and producing the product. For the years 2016-2020. Part I. - Tashkent: SRIA, 2016. p.140.

[2] System of machines and technologies for complex mechanization of agricultural production for the years 2011-2016. Part I. - Tashkent: UzSIMEA, 2013. - p.199.

[3] Akhmedjanov M.A. Levelling the irrigating lands. Tashkent, 1991. - p.112.

[4] TSt 63.04:2001. «Tests of agricultural equipment. Machines and tools for surface of the soil tillage. Programme and methods of tests». // Official edition. - Tashkent, 2001. p.54.

[5] O'Z DSt 3193: 2017. «Tests of agricultural equipment were determined based on methods of power assessment of the machines». // Official edition. - Tashkent, 2001. - p.67.

[6] Dospekhov B.A. Method of field trials. - Moscow: Kolos, 1978.- p.335. 